\title{
The effect of curricula approaches to the development of the student's clinical reasoning ability
}

\author{
T Khanyile, PhD \\ School of Nursing, University of the Western Cape \\ F Mfidi \\ University of Transkei
}

\section{Keywords:}

Approach, content-based, curriculum, clinical reasoning. learning, problembased, traditional.

\section{Correspondr ^ ce address:}

Porf Thembesile Kh, lyile

School of Nursing

Community \& Health Science Faculty

University of the Western Cape

Bellville

7535

South Africa

Tel: (021) 959-3003

Fax.: (021) 959-1482

Email:tkhanyile@uwc.ac.za

\section{Abstract: Curationis 28(2): 70-76}

A comparative analysis was undertaken using descriptive and cross sectional survey design, to explore the effect of Problem Based Learning and Traditional approach on the development of clinical reasoning abilities of nursing students.

Using quota sampling, a sample of 87 subjects was used from two University Nursing Departments, each using these curricula approaches. Students from their first, second and fourth year were interviewed, using the Triple Jump Exercise as an instrument to collect data. Data analysis using the SAS computer software package was employed to obtain both descriptive and statistical summarizations.

Though descriptive analysis of the scores of clinical reasoning showed a slight difference between the two curricular approaches, this was not confirmed statistically as the two factor ANOVA and Tukey's methods revealed no significant differences by approaches. The only significant difference was revealed between the students' levels of study with senior levels ( $4^{\text {th }}$ years) outperforming their juniors. These findings therefore conclude that, students using Problem Based Learning and Traditional approach perform on a similar level in clinical reasoning.

\section{Introduction}

With the transformation of the health and education systems in South Africa, the South African Nursing Council (SANC) emphasized teaching and learning strategies that will enhance studentcentred education and training with a focus on the community health needs (SANC 1999). In response to this, Nursing Education Institutions have begun to introduce innovative approaches like Community Based Education (CBE); Problem Based Learning (PBL) and Case Based Learning (CBL). The adoption of problem based learning as a curriculum approach was viewed as an effort to move away from the content-focused learning approach. This was seen as an effort to develop students' critical and clinical reasoning abilities together with selfdirected learning (Barrows, 1985: 59; Boud and Felleti, 1991: 104).
Clinical reasoning skills are seen as the cornerstone for successful nursing practice. Various authors have conceptualised clinical reasoning as encompassing all the thinking processes nurses engage in during their practice. Barrow and Pickel (1991: 76) defined clinical reasoning as: a dynamic, cyclical, reiterative process in which observation, analysis, synthesis, deduction, induction, hypothesis generation, hypothesis testing, inquiry-strategy design and the skills of examination are all interrelated (Barrow, 1994:125). Therefore, clinical reasoning, clinical decision making, clinical judgement and the scientific method are seen as terms used interchangeably. Others view critical thinking as a component of clinical reasoning in nursing practice (McCloskey \& Grace, 1997:64; Girot, 2000:93). On the other hand, some view clinical reasoning as a component of 
critical thinking. In their model of critical thinking, in an attempt to provide a domain specific definition of critical thinking, Kataoka- Yahiro and Saylor described critical thinking as a reflective and reasonable thinking about nursing problems without a single solution which is focused on deciding what to believe and do. They further stress that critical thinking competencies include diagnostic reasoning, clinical reasoning, clinical decision making and the nursing process. These conceptualisations account for the overlap in the usage of the concept clinical reasoning and critical thinking in nursing practice (KataokaYahiro \& Saylor 1994:309).

Clinical supervision, according to Jenks, 1993 is a regular, protected time for facilitated, in-depth reflection on clinical practice with an aim of helping the student to achieve, sustain and creatively develop a high quality of practice through focused support and development. Therefore, clinical supervision is the umbrella term used to describe the methods used by teachers to help students in their development of clinical reasoning (Jenks, 1993 :399).

To date much has been written about the effectiveness of PBL especially in medical education (Barrows, 1994:236; Hawkins 2002:215; Davis \& Harden, 1999:37; Mhlauli \&Khanyile, 1999:53; Khumalo \& Gwele 2000: 108), and most research on this approach has been on the attitudes of nurse educators, students; and implementation problems. The reason for this may be that PBL has been a relatively new concept in South Africa and hence the focus has been only on its acceptability and implementation. On the other hand, a study was conducted by Mtshali and Khanyile (2001:89), to compare the ethical decision making skills of students from both approaches. According to the results, there was no significant difference between the two groups of students' ethical decision making skills. It becomes evident then that, although much has been written about the potential benefits of PBL, there is little empirical evidence to support this.

\section{Problem statement}

The use of these two curricular approaches in pre-registration programs. that is problem based learning and traditional content-based approach, has raised much interest and debate as to whether it is the approach alone, or there are other factors that will ensure the production of competent nurse practitioners with expert clinical reasoning skills essential for providing highly skilled quality care grounded in sound knowledge of the science of nursing. In clinical teaching situations, endeavours are made to link what is taught in the classroom and what is experienced in the clinical setting thus bridging the theory-practice gap. This is done to ensure development of competent practitioners with the ability to provide safe, competent care which Taylor (2000:840), describes as depending on good clinical problem solving skills. It becomes imperative therefore to gain better understanding of cognitive problem solving strategies used by nurses in clinical practice and approaches that best enhance this development. The question is: which of the two approaches best enhance the development of clinical reasoning ability?

\section{Purpose of the study}

The study sought to explore and describe the effect of problem based learning and the traditional approach to the development of the students' clinical learning abilities.

\section{Research questions}

1 How do the clinical reasoning abilities of basic nursing students from the traditional approach compare with those from the Problem Based Learning approach?

2 Is there progression in the development of students' clinical reasoning abilities as they progress within the two programs?

\section{Hypothesis}

It was hypothesised that, between the two groups of students:

1 Clinical reasoning skills of the group following the PBL approach will be better than those following the traditional approach.

2 The progression in the development of clinical reasoning skills from entry to exit will be higher for the PBL group than the traditional group.

\section{Operational definitions}

\section{Clinical reasoning}

In the context of this study, clinical reasoning is a dynamic, cyclic, reiterative process in which observation. analysis, synthesis, deduction, induction, hypothesis generation, hypothesis testing, inquiry- strategy design and the skills of examination are interrelated (Barrow \& Pickel, 1991:121). The terms clinical judgement, clinical decision making and problem solving, clinical reasoning has been used synonymously and interchangeably throughout the study.

\section{Student}

A person following the basic nursing programme according to the South African Nursing Council regulation R425 of 1985 as amended.

Comprehensive basic nursing programme An integrated basic nursing programme offered either at a degree or diploma level, with a duration of 4 years, leading to registration as a general nurse, midwife, psychiatric and community health nurse (SANC, 1985).

\section{Teaching approach}

Strategies of instruction and learning used in the teaching -learning situation.

\section{Traditional approach}

A didactic model used to deliver instruction both in the classroom and clinical settings is used with more reliance on content coverage and objectives testing.

\section{Problem -based learning}

In this approach, active involvement of the student is fostered and the role of the teacher is facilitative with learning resulting from the process of working towards the understanding or resolution of a problem (Barrows, 1985:104).

\section{Conceptual framework}

Models explored were the Nursing Process model, Outcomes model, Present state Testing model and the Hypotheticodeductive models. The model most appropriate for the study was the Hypothetico-deductive model. This model emanated from empirical work of Elstein \& Bordage in 1997, who analysed the judgements of physicians and discovered that their judgement was not intuitive but rather based on a cognitive strategy called hypothetico-deductive reasoning approach (Elstein \& Bondage, $1997: 111)$. The model has the following stages:

(a) Initial concept formation

Initial concept formation is activated by 
the patient encounter. Additional information is gathered through observation based on additional information that the patient may present. During this stage, the practitioner selects pivotal findings which are used to bridge the gap from the presenting problem and the practitioner's extensive knowledge base. The information perceived during this encounter is continually analysed and assembled into an initial concept through the reasoning process.

\section{(b) Hypotheses generation}

As the clinician assembles the initial concepts, a number of hypotheses emerge. Through an inductive process of lateral thinking the practitioner thinks of possible conditions suggested by the patient's presenting problems. This stage provides a guideline as to what kinds of data to gather in order to define the patient's problems and to manage it successfully.

\section{(c) Inquiry stage}

This step aims at obtaining more or new information beyond that initially presented. Barrow and Pickel (1991:68), view this stage as a disciplined, logical, vertical, deductive cognitive process used to select particular strategies and clinical skills to be used for data collection in support or refuting the hypothesis.

\section{(d) Data analysis and synthesis}

Data accumulated during the inquiry stage need to be organized so as to formulate the problem. Hypothesis testing occurs during this stage as well as the identification of cause and effect relationships.

\section{(e) Diagnostic and treatment decision}

This is the end result of clinical reasoning that ends the encounter between the nurse and the patient. The nurse clinician decides what the underlying responsible mechanism involved in the patient's problem is and selects strategies to modify, correct or manage the problem identified.

\section{Methodology}

\section{Research design}

The study utilized a comparative descriptive survey. The clinical reasoning abilities of the two groups of students were described in relation to the different curricular approaches. As one of the objectives was to determine progression levels of clinical reasoning abilities from entry level to exit level, cross- sectional data was used to examine difference in various levels of training.

\section{Target population}

The target population consisted of all students following the degree in Nursing (General, Community, Psychiatry) and Midwifery according to SANC Regulation R 425 at two selected universities in the country. One group from one university was using PBL whilst the other group from the second university was using the traditional approach. There was a total of 180 students from institution A (PBL group) and a total of 234 students from institution B (Traditional group).

\section{Sampling and sampling technique}

Quota sampling was used where $10 \%$ of the first year group was sampled from each university, $45 \%$ second year and $45 \%$ fourth years as indicated in table 1 . The sample of $1^{\text {st }}$ year students was deliberately minimal since they were only included to obtain baseline information while $2^{\text {nd }}$ and $4^{\text {th }}$ year students were included as they met the eligibility criteria for a minimum period of clinical exposure in medical and surgical units of plus minus 1 year. Third year students were excluded as it was felt that the difference of a year between the levels would not give a much observable picture of the students' progression in clinical reasoning skills. The progression was to be observed from the $2^{\text {nd }}$ to the $4^{\text {th }}$ level.

\section{Table 1: Sample size from the two approaches}

\begin{tabular}{|l|l|l|}
\hline Level & $\begin{array}{l}\text { Institution A } \\
\text { Traditional }\end{array}$ & $\begin{array}{l}\text { Institution } \mathrm{B} \\
\text { PBL }\end{array}$ \\
\hline 1 & 9 & 11 \\
\hline 2 & 14 & 14 \\
\hline 4 & 19 & 20 \\
\hline Total & 42 & 45 \\
\hline
\end{tabular}

\section{Data collection procedures}

The Triple Jump Exercise was used as an instrument to collect data. The Triple Jump Exercise is a structured exercise consisting of three parts or steps which are the (a) problem definition, (b) information search and study and (c) problem synthesis formulation and intervention. It is an experiential exercise which allows the student to observe and evaluate problem solving behaviours while simultaneously verifying their self awareness with another person (examiner). The objectives of using this exercise are to assess the individual student's ability to generate hypothesis from a given situation, seek out and critique relevant data. develop either a diagnosis or management (care) plan to evaluate his or her own performance in the exercise (Vernon \& Blake, 1993:559). The Triple Jump Exercise is a wellrecognized approach to assess problem solving and critical thinking skills. This exercise is commonly used by institutions using the PBL approach, however both institutions in the study were not using Triple Jump in other words both groups were not familiar with the exercise, although Institution $B$ was using PBL as an approach to teaching and learning. The instrument was administered through individual interviews with the two groups of students from the two universities. A clinical scenario was used to present the subjects with a problem for analysis. The scenario analysis was allocated 30 minutes, after which each subject was evaluated in all 4 phases (problem definition, data collection, problem definition and nursing intervention) of the instrument. Using the questions in the evaluator's notes as an interview guide, responses were elicited from subjects. Subjects were to think aloud when analysing the scenario whilst the researchers took down notes of the responses verbatim. Audio tape recording was done to complement the notes.

\section{Reliability}

The set of items in the Triple Jump instrument has a certain degree of internal consistency since they measure critical attributes of the problem solving process, namely problem definition, data collection, problem identification and initiation of a nursing intervention. Measures to ensure interrater reliability were made by using two examiners (researcher and an assistant) to rate the subjects independently during 


\begin{tabular}{|c|c|c|c|}
\hline Clinical Reasoning & Triple Jump Exercise & Student Instructions & $\begin{array}{l}\text { Researchers' questions to } \\
\text { students }\end{array}$ \\
\hline Problem definition & $\begin{array}{l}\text { 1. Issue identification } \\
\text { 2. Question generation }\end{array}$ & $\begin{array}{l}\text { 1. Read the problem card } \\
\text { presented to you. } \\
2 \text {.You have to identify issues/ } \\
\text { questions which you think are } \\
\text { relevant to this situation. }\end{array}$ & $\begin{array}{l}\text { Question posed to student: } \\
\text { What important nursing } \\
\text { issues can be derived from the } \\
\text { presenting situation? }\end{array}$ \\
\hline Data collection & $\begin{array}{l}\text { 3. Systemic data collection } \\
\text { (proceeds from clients } \\
\text { problem) } \\
\text { 4. Use of cues in data collection } \\
5 . \text { Amount of data collected. } \\
(80 \%)\end{array}$ & $\begin{array}{l}\text { On request, the researcher will } \\
\text { supply you with information } \\
\text { from the patient's record, to } \\
\text { help you to formulate the } \\
\text { problem. }\end{array}$ & $\begin{array}{l}\text { What questions would you } \\
\text { like to ask in order to } \\
\text { understand the problem? } \\
\text { What knowledge directs your } \\
\text { questioning? Or why do you } \\
\text { ask these questions? }\end{array}$ \\
\hline Problem formulation & $\begin{array}{l}\text { 6. Use of current knowledge to } \\
\text { guide data collection. } \\
\text { 7. Ability to think through } \\
\text { unfamiliar concepts. }\end{array}$ & $\begin{array}{l}\text { You have to summarize and } \\
\text { formulate a nursing inter- } \\
\text { vention. }\end{array}$ & $\begin{array}{l}\text { Please summarize the major } \\
\text { problems and issues related } \\
\text { to this situation. } \\
\text { What findings support your } \\
\text { summary? } \\
\text { What is your rationale? }\end{array}$ \\
\hline Nursing intervention & $\begin{array}{l}\text { 8. Accuracy and preciseness } \\
\text { of problem formulation } \\
\text { 9. Able to describe most } \\
\text { important nursing inter- } \\
\text { ventions. }\end{array}$ & $\begin{array}{l}\text { Describe the nursing } \\
\text { intervention you will initiate, } \\
\text { giving a rationale for each } \\
\text { action. }\end{array}$ & $\begin{array}{l}\text { What nursing intervention } \\
\text { will you initiate and why? }\end{array}$ \\
\hline
\end{tabular}

interviews and thereafter comparing their ratings. Moderation of the scores was also a team effort by the researcher and the two research assistants.

\section{Validity}

Content validity was ensured by using the Triple Jump Exercise as the data collection instrument. As mentioned earlier, the Triple Jump Exercise has a selfevident measure of the adequate coverage of all the elements of the concept clinical reasoning that this study sought to investigate.

\section{Ethical considerations}

Permission was obtained from the Heads of the two institutions and the subjects all signed an informed consent. No names were used in the researcher's notes and evaluation forms. Pre-determined codes were used to identify the information with the subject from each group. Subjects were assured of anonymity.

\section{Data analysis}

The rating and moderation of the subjects' responses was done jointly by the research team. Narratives were rated on a five item scale used for the Triple Jump Evaluation form with 1-2 rated as lowest performance; 3 as borderline, 4 as acceptable performance and 5 as excellent performance.

\section{Results}

Results were analysed to determine the total mean scores of the two groups, to determine variations in their performance by the different levels of training of the two groups; to compare similarities/ variation in performance of the two groups between similar levels and lastly to determine variation in performance by comparing the two approaches.

\section{Total mean scores of the clinical reasoning abilities of the two groups}

Mean scores of students from the PBL and traditional approach group. Marked differences were shown between the scores of the lower and higher levels of training with the first and second year levels scoring lower than their senior counterparts. The mean scores for the traditional $4^{\text {th }}$ years were 29,3 with a standard deviation of 7,1 while the PBL $4^{\text {th }}$ years were 30,05 with a standard deviation of 6,3 (see table 3 ).

\section{Performance by different levels of the same group}

Differences among the three levels of training within same groups were identified. In the Traditional learning group, the performances of the second years were lower than that of the $4^{\text {th }}$ years with a mean difference of 6.8 . The same pattern was observed in the PBL groups with a mean difference of 5,3 between the second and fourth year students. When the same levels of the two groups were compared, slight differences were identified. Between the $4^{\text {th }}$ year levels the difference in their performance was 1.2 
Table 3:Total mean scores of clinical reasoning abilities of all groups.

\begin{tabular}{|l|l|l|l|}
\hline Approach & Level & Mean & Std. Dev. \\
\hline \multirow{4}{*}{ Traditional } & 1 & 19,9 & 1,5 \\
\cline { 2 - 4 } & 2 & 22.5 & 4,2 \\
\cline { 2 - 4 } & 4 & 29.3 & 7,1 \\
\hline \multirow{3}{*}{ PBL } & 1 & 21,7 & 2.9 \\
\cline { 2 - 4 } & 2 & 24,7 & 4,7 \\
\cline { 2 - 4 } & 4 & 30.05 & 6.3 \\
\hline
\end{tabular}

while in the $2^{\text {nd }}$ levels it was 2.2 . From these findings, it is evident that as the levels of study increase, a marked improvement in the students' clinical reasoning occurs.

\section{Mean scores in various phases of Triple Jump Exercise (TJE)}

Interpretation of performances of the two groups on the 4 phases of the TJE was made possible by splitting the total scores of clinical reasoning according to the 9 evaluation items in the evaluation form as indicated in table 4 .

Levels of study within and between groups displayed no conspicuous variability by mean scores in the various items. A mean difference of 0.2 was found in these performance scores and this was not sufficiently significant to establish the existence of differences in performance. Again higher levels of study revealed better performances than the lower levels in all items contained in the instrument.

All the levels $1^{\text {th }}, 2^{\text {nd }}$ and $4^{\text {th }}$ performed poorly in the amount of data collected (less than $80 \%$ ). According to the instrument $80 \%$ of data collected is adequate to initiate intervention for the problem situation.

To substantiate this descriptive statistics and to determine the effect of the independent variable (curricular approach) $t \rightarrow$ the dependent variable (clinical reasoning), two factor analysis of variance and interaction tests were employed using total mean scores of both groups. The question to be answered was whether differences in the scores were due to the curricular approaches used, or whether it was only the differences in the levels of training that made the difference or whether it was both.
Results revealed that neither approach used nor the levels of training had a significant effect on the subjects' clinical reasoning scores with $p=0,21$ for TDL and $0,8 \mathrm{PBL}$

The levels of study were the factors that had a significant effect on the scores at $p=0.0001$ (See Table 5). According to the results both hypotheses one and two were rejected.

A post-ANOVA test, using Turkey's method was done to establish and substantiate the ANOVA results, by identifying where the significant differences amongst levels of study were. The results confirmed significant differences among the lower levels and higher levels of study at a $p$ value of 0.05 . Between $4^{\text {th }}$ year levels and $2^{\text {nd }}$ year levels with lower confidence limits of 2.9 and upper confidence limit $=$ 9.2, differences were observed $(6.075$ mean difference). Between $4^{\text {th }}$ year levels and 1 "year levels with lower confidence limits (12.264), there was a mean difference of 8.768 . Between $2^{\text {nd }}$ year levels and $\mathrm{I}^{\mathrm{st}}$ year levels no significant difference was marked.

\section{Discussion}

Total scores of the two groups on clinical reasoning abilities provided a composite picture of group performances in the clinical reasoning processes as measured by the Triple Jump exercise. Variations according to levels of study in both groups were identified, with senior levels performing better than their junior counterparts. From these results, it can be deduced that as students progress throughout from first year to fourth year, their clinical reasoning abilities improve. Benner, cited in Maynard (1994:103), contends that this is due to exposure to clinical experiences.

The $4^{\text {th }}$ years have more clinical exposure than the $1^{\text {st }}$ or $2^{\text {nd }}$ years and hence their higher performance. Kataoka \& Saylor (1994:353) also support the importance of clinical experience (environment) an important component in competence development. Sedlack (1997:14) also alluded to the importance of clinical environment to the development of students' critical thinking skills. The results of this study also refuted the conclusion that curriculum approach has an effect on clinical reasoning. In other words, there are other factors that influence the student's clinical reasoning ability rather than only the approach used.

The results showed no conspicuous difference by approaches. The PBL group had been expected to perform better because of the hypo-deductive model used in this approach, although the specific instrument was not familiar to them.

\section{Limitations}

The sampling technique used which was a non-probability technique limit the representativeness of the study sample and hence the generalisations of findings was weakened. The two research settings used were within the same region and they might share similar problems, for an example limited resources that would impose a negative impact on student learning and thus affect the results of the study. Studies undertaken in other regions might reveal different findings

\section{Recommendations}

The findings of this study challenge nurse educators using the PBL approach to investigate the demonstrability of the end results of PBL. The findings challenge teaching and learning, for an example, the Case Based Learning approach. Deretchin (1999:64) also support the use of PBL alongside other approaches in a mixed curricular format. According to them this results in learners using deeper approaches to learning which is lacking in the PBL only approach and they show preference for active forms of learning and the use of a variety of learning resources.

The Case Based Learning approach utilizes case studies as its teaching strategy and it stimulates ideas through complex problem-analysis of actual or hypothetical situations and provides a means of applying theoretical principles to practice. It is recommended as an effort to balance the limitations of both the PBL and the traditional content-based approach. It is also recommended for nurturing clinical reasoning skills based on the following characteristic features:

- Teacher guided as the teacher prepares the learning outcomes of the case

- $\quad$ Student oriented and student controlled as student take an active role in preparing for presentations. This method is 
Table 4: Performances in each evaluation item by all levels of the study

\begin{tabular}{|c|c|c|c|c|c|c|c|}
\hline \multirow[b]{2}{*}{$\begin{array}{l}\text { Clinical } \\
\text { reasoning } \\
\text { phases }\end{array}$} & \multirow{2}{*}{$\begin{array}{l}\text { Approach } \\
\text { Evaluation } \\
\text { items in } \\
\text { Triple } \\
\text { Jump Exercise }\end{array}$} & \multicolumn{3}{|c|}{ Traditional } & \multicolumn{3}{|c|}{ Problem Based Learning } \\
\hline & & Level 1 & Level 2 & Level 4 & Level 1 & Level 2 & Level 4 \\
\hline & & M SD & M SD & M SD & M SD & M SD & M SD \\
\hline Problem definition & $\begin{array}{l}\text { Issue identification } \\
\text { Question generation }\end{array}$ & 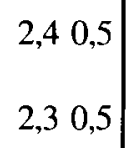 & $\begin{array}{l}2,60,7 \\
2,6 \\
0,5\end{array}$ & $\begin{array}{l}3,10,8 \\
3,2 \quad 1,0\end{array}$ & $\begin{array}{ll}2,7 & 0,8 \\
2,4 & 0,5\end{array} \mid$ & $\begin{array}{l}2,91,3 \\
2,90,9\end{array}$ & $\begin{array}{l}3,70,5 \\
3,20,7\end{array}$ \\
\hline \multirow[t]{3}{*}{ Data collection } & $\begin{array}{l}\text { Systemic data collection } \\
\text { Use of cues in data } \\
\text { gathering }\end{array}$ & $\begin{array}{ll}2,2 & 0,4 \\
2,3 & 0,5\end{array}$ & $\begin{array}{l}2,50,5 \\
2,60,6\end{array}$ & $\begin{array}{l}3,21,2 \\
3,31,1\end{array}$ & $\begin{array}{ll}2,4 & 0,5 \\
2,7 & 0,5\end{array}$ & $\begin{array}{l}2,40,7 \\
3,1,9\end{array}$ & $\begin{array}{l}3,30,7 \\
3,40,9\end{array}$ \\
\hline & $\begin{array}{l}\text { Knowledge guiding } \\
\text { data collection }\end{array}$ & $2,20,4$ & $2,40,9$ & $3,11,2$ & $1,90,5$ & $3,10,9$ & $3,41,0$ \\
\hline & $\begin{array}{l}\text { Amount of data } \\
\text { collected }\end{array}$ & 2,00 & $2,20,4$ & $3,00,9$ & $2,00,5$ & $2,40,7$ & $2,81,1$ \\
\hline \multirow[t]{2}{*}{ Problem formulation } & $\begin{array}{l}\text { Data analysis, use of } \\
\text { current knowledge }\end{array}$ & $2,00,4$ & $2,40,6$ & $3,21,1$ & $2,40,8$ & $2,8 \quad 0,9$ & $3,21,0$ \\
\hline & Accuracy & $2,10,3$ & $2,40,6$ & $3,50,8$ & $2,40,8$ & $2,90,7$ & $3,40,9$ \\
\hline Nursing intervention & Appropriateness & $2,40,5$ & $2,90,8$ & $3,80,9$ & $2,80,8$ & $3,10,5$ & $3,70,7$ \\
\hline
\end{tabular}

nursing practice today.

There is a need for further research to address other complexities in the clinical teaching environment on the development of clinical reasoning skills. PBL has been promoted for its effectiveness in producing selfdirected learners but as nurse educators we need not be blinded by these promises. $\mathrm{S} t$ u d e n t accompaniment, the creation of a conducive clinical l e a r n i n g environment by being there for the students, if done effectively can still do the trick. The theory-practice gap still remain after PBL.

more useful than PBL in situations where learning resources, especially human resources are a problem in most Institutions of Higher Learning.

\section{Conclusion}

The findings of this study contradict findings of Hmelo's study (1998), cited by Huey (2001:72), which revealed that PBL students perform better than traditional students in generating explanations that were more accurate, coherent and comprehensive. The findings also rejected the hypothesis that the progression in the development of

clinical reasoning skills entry to exit will be higher for the PLB group than the Traditional group. Therefore the results of this study lay a foundation for nurse educators to look beyond the approach used for teaching and learning and to begin to consider the context of learning in a broader sense than just the approach used. Clinical support, through accompaniment could still be regarded as having a positive influence on the development of clinical reasoning. Clinical reasoning remains the crux of expert practice and one of the most demanded skills for nurses to be able to deal with increasing complexities of

Table 5: ANOVA results on differences in total mean scores by levels of study and curricular approaches

\begin{tabular}{|l|l|l|l|l|}
\hline Focus & DF & SS & Mean & P value \\
\hline Study level & 2 & 1199.1608 & 599.5804 & 0.0001 \\
\hline Approach & 1 & 44.8464 & 44.8464 & 0.2120 \\
\hline Level\& approach & 2 & 11.0196 & 5.5098 & 0.8237 \\
\hline
\end{tabular}

\section{References}

BARROWS, HS 1985: How to design problem based curriculum for pre- clinical years. New York: Springer Publishing Co.

BARROW, HS 1994: Practice- based learning. Problem -based learning applied to medical education. Springfield: Southern Illinois University of School Medicine.

BARROWS, HS \& PICKEL, GC 1991: Developing clinical problem solving skills. A guide to more effective diagnosis and treatment. New York: WW Norton \& Company.

BOUD, D \& FELLETI, G 1991: The challenge of problem -based learning. New York: St. Martin's Pres Inc.

DAVIS, FP \& HARDEN, C 1999: Learning styles and approaches in medical education. Education for Health. 12(2).

ELSTEIN,AS \& BORDAGE, G 1997: Medical problem solving: An analysis of clinical reasoning . Cambridge, MA: 
Harvard University Press.

GIROT, EA 2000: Graduate nurses: critical thinkers or better decision makers? Journal of Advance Nursing. 31, (2), 288297.

HAWKINS,R 2002: Clinical evaluation in advanced practice nursing education: using standardized patients in health assessment. Journal of Nursing Education, 41(5), 215-219.

HUEY, D 2001: Potential utility of problem- based learning in the education of clinical psychologists an others. Education for Health. 14, (1), 11-19.

JENKS, JM 1993: The personal knowing in a nurse clinical decision making. Journal of Nursing Education. 32 $(0,399-405$.

KATAOKA- YAHIRO, M \& SAYLOR, C 1994: Critical thinking models for nursing judgement. Journal of Nursing Education. 33 (8), 351- 356.

KHUMALO, M \& GWELE, NS 2000: Perceptions of nurse educators about PBL. Curationis. 2(1), 57-62.

MAYNARD, CA 1996: Relationships of critical thinking ability to professional nursing competence. Journal of Nursing Education. 35 (1).

McCLOSKEY,JC \& GRACE, HK 1997: Current issues in nursing ( $5^{\text {th }}$ edition) St. Louis: Mosby -Year book. Inc.

MHLAULI, N \& KHANYILE, T 1999: Perception of nurse educators on problem based learning in Region $E$ of the Eastern Cape. Unpublished dissertation, Durban: University of Natal. (M.Cur Thesis).

MTSHALI, N \& KHANYILE, T 2001: Comparative analysis of ethical decision making in comprehensive basic nursing students. Curationis. 3 (1),

SEDLAK, CA 1997: Critical thinking of beginning Baccalaureate nursing students during their first clinical course. Journal of Nursing Education. 36 (10), 11 18.

SOUTH AFRICAN NURSING COUNCIL, 1985: 425:Regulations relating to the approval and minimum requiremẹnts for education and training of a nurse leading to registration as a nurse (General, Psychiatry, Community ) and Midwife,. Pretoria: SANC.

SOUTH AFRICAN NURSING COUNCIL, 1999: Education and training of professional nurses in South Africa. Guidelines for transforming Nursing Education. A discussion document. SANC: Pretoria.

TAYLOR, C 2000: Clinical problem solving in nursing: insights from literature. Journal of Advance Nursing. 31 (4), 842-849.

VERNON, DT \& BLAKE, RL 1993: Does problem based learning work? A meta- analysis of evaluative research. Academic Medicine. 68(7), 550- 563. 